\title{
Comparative Study of Iran and the UK national curriculum based on the principles of Mind, Brain and Education
}

\author{
Nazanin Rezazadeh Mottaghi ${ }^{1, *}$ \& Mahmoud Talkhabi ${ }^{2}$ \\ ${ }^{1}$ The Institute for Cognitive Science Studies, Pazhouheshkadeh Blvd, Safir Omid Blvd. ${ }^{\text {th }}$ Phase, Pardis New City \\ (15 KMs North East of Tehran), Iran \\ ${ }^{2}$ Department of Elementary Education, Chamran Campus, Farhangian University, Tehran, Iran \\ *Correspondence: The Institute for Cognitive Science Studies, Pazhouheshkadeh Blvd, Safir Omid Blvd. 4th Phase, \\ Pardis New City (15 KMs North East of Tehran), Iran. Tel: 98-21-7629-1130. E-mail: rezazade.n@gmail.com
}

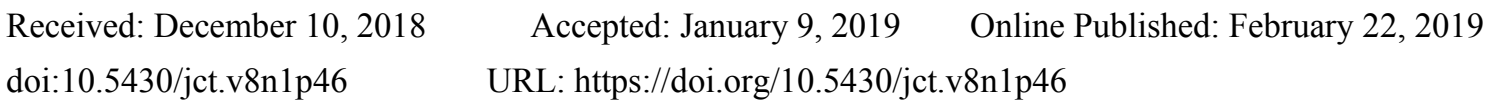

\begin{abstract}
This study compares the national curriculum of Iran and the UK to find out how the educational system in developing countries such as Iran can be improved. Because of implementing thinking skills and cognitive education, the educational system in the UK benefits from a high-quality standard. The science of mind, brain, education introduces some principles to improve teaching and learning methods and provide thoughtful and lifelong learners for the societies. In this study, we specified the main parts of the national curriculum in both countries and selected some of the principles to determine whether these two countries apply them in their national curriculum. Some of these principles focus on some significant issues: teaching models, the use of Meta-discipline and Holistic Techniques, authentic learning experiences, use of products, processing and progressing Evaluations, developing explicit learning objectives, how to benefit from thinking and reflective practices, using collaborative and democratic activities, preparing students to set personal objectives, giving themselves feedbacks, technology and flipped classrooms, and beginning Year- Round Schooling. The results show that Iran needs more precise and detailed learning objectives in its curriculum, use of democratic and collaborative activities with academics and students, develop thinking and reflective practices which play vital roles in upgrading the educational system. Moreover, it is suggested that the UK and Iran should consider embedded evaluations and flipped classrooms to meet the needs of new generation of learners.
\end{abstract}

Keywords: comparative study, national curriculum, mind, brain, and education principles, cognitive education

\section{Introduction}

In many countries, there is a program called "National Curriculum" for purposeful training of students in schools, which is one of the underlying systems of Education, and a comprehensive pattern of learning for an inclusive and in-depth change in educational concepts and content. The program seeks to provide diverse and extensive educational programs for students to achieve the required level of competency. In the national curriculum, goals, values, and intentions have been proposed in accordance with which training strategy should be undertaken. In fact, the national curriculum is an important element of the school curriculum, and it leads to the formation of school curricula. Therefore, each school has a curriculum which needs to be targeted according to the national curriculum. In this regard, this mission (preparing the national curriculum) is to provide appropriate mechanisms for designing, compiling, implementing and evaluating curricula at the national and local levels in order to provide systematic and structured education concepts for children and adolescents and to arrange an amusing educational environment. On the other hand, the world is changing rapidly based on revolution in ICT in which thinking process would be in the center. Therefore, instead of knowledge-based schools, we need thinking-center based schools because knowledge does not equal understanding and ability, and this requires a cognitive approach in schools to provide opportunities for intellectual development, and students can apply these skills in their curriculum(Jefferies \& Hancock, 2002). Consequently, in light of the statements which were made earlier, we now have to start with the national curriculum in order to implement this approach in schools. One of the countries that have taken such action is England. England 
has revised the national curriculum in 2000, which has provided opportunities in order to facilitate learning through concentrating on direct development of children's thinking skills. Therefore, cognitive schools were established in this country, the curriculum of which was based on teaching thinking skills. This study actually compares the national curriculum of Iran and the UK and examines their differences and their cognition based on mind, brain, and education principles. The implementation of these benchmarks in the National curriculum is a step towards a cognitive approach in schools that reinforces thinking skills.

\section{Theoretical Framework}

With the revolution of cognition, there has been a lot of transformation in education and learning that, as a result of these developments, societies have moved from accepting knowledge to creation of knowledge, from gaining knowledge to knowledge management and from systems of thought to the use of intellectual tools. The science of mind, brain, education, which consists of educators, neuroscientists and psychologists, uses both information from the lab and the classrooms to improve the learning outcomes and begins with the assumption that education issues are complex and therefore they require answers from a multidisciplinary look. Therefore, it introduces principles in order to create a profound educational background in research and to have more effective and efficient teaching. It is a common knowledge that the school is the largest educational institution and the right environment for education and the best place that can affect the transcendental growth of humans. As a result, each country has a special system for school education according to its aspirations and prospects.

Since our country and many other countries, including the United Kingdom, have adopted a national curriculum to achieve these aspirations and perspectives. It is trying to make this document a path that is actually a road map of the program Curriculum development and preparation of plans as well as a guide to the preparation, formulation, and implementation of executive practices and practices for school administrators and teachers.

The National Curriculum is a general framework for the education system with regarding to the individual and local differences are in order to achieve the goals of national education. The basis of the preparation and formulation of curricula is everywhere the ideals and perspectives of the system for the promotion of the country and the training of human resources, which itself is the basis for the formulation of goals, methods, strategies and approaches.

\section{National Curriculum}

The National Curriculum is a major source of resources, with all the necessary requirements, storage of any type of curriculum, and the production of any curriculum. Therefore, the national curriculum is a document used at the macro level of the system and the national curriculum is a set of criteria and standards that are coordinated and systematic in the preparation and production of all curricula in the country and are based on research findings. In other words, the National Curriculum is a major plan that draws up country policies and curriculum by defining goals, standards, and educational expectations to explain the importance of the components, based on research grounds and logic (Raisdana, ROSHD information technology, 2010).

\section{Cognitive Approach to the National Curriculum}

\subsection{Cognitive Education}

Cognitive education is a strategy for learning and teaching. The main purpose of this strategy is to develop and encourage systematic processes of perception, thinking, learning, and problem solving. The uniqueness of cognitive approaches to education is initially because systematic thinking is the first objective of education. Another aspect of cognitive education is that there are learning useful tools which may be necessary for effective learning. Cognitive educators have their own tools, yet they all have common characteristics, all of which include a core of formal thinking processes that act as metacognitive and cognitive functions, cognitive structures, and mental habits, learning tools and creating thinking blocks. The third characteristic is concentrating on the process of thinking and learning (how one learns) rather than exclusive focus on content (Haywood, 2013). Cognitive education emphasizes on the existence of a balance between learning content and learning process in which how to learn is of great importance. Dynamic assessments show that the effectiveness of learning can be improved by focusing on people's attention and efforts on the processes by which they apply their intellectual resources. For example, it is not sufficient for a carpenter to be given a hammer and a saw, and frequently some instruction to accomplish tasks. The vast differences are seen in how those tools are used. In fact, "there are enormous individual differences in the ways in which 
different carpenters combine and employ their available resources- not only the primary tools, but also their personal resources- and prior knowledge" (Haywood, 2013, p. 29) .

\subsection{Thinking Skills}

According to Jefferies and Hancock, thinking skills are useable and functional tools for teachers to enable them to plan for the explicit training of core skills throughout the curriculum to support learning activities. These tools can help children to make a connection between real situations and skills, and then understand their learning purposes(Jefferies \& Hancock, 2002). Jefferies and Hancock have divided thinking skills into five categories that are included:

- Information Processing Skills

- Reasoning Skills

- Enquiry skills

- Creative Thinking Skills

- Evaluation skills

They believe that this framework can be mix with all the subjects of the national curriculum.

Clarifying thinking skills gives us the opportunity to focus on teaching thinking. Therefore, learners in schools and classes are allowed to see learning relationships, understand how to think and learn, and apply skills within and outside the curriculum.

\section{Mind, Brain and Education Principles}

The science of mind, brain, and education provide some principles for designing lessons, activities, and evaluations in order to help students to be real learners. According to Takuhama-Espinosa in "making classrooms better" book, each learner including normal people those have learning disabilities and/or gifted talents can take advantage of their potential through their lives (Tokuhama- Espinosa, 2014). In this study, we selected some specific principles from the studies of mind, brain, and education to conduct a research on the national curriculum of Iran and the UK based on these principles and examine to what extent two national curriculums have been able to implement these scientific principles. The principles which are related to the national curriculum are as follows:

\subsection{Teaching Models}

Varied teaching methods and activities conducted in the classroom, can play a significant role in learning in any subject matters. The more we upload knowledge to our brain in a variety of ways, the easier it will be remembered. Research results show that if the same information is trained in different ways, it will be more likely to remind and transfer the information (O'Donnell, A.M., Dansereau, D.F.,\& Hall, R.H., 2002). In most classrooms, the dominant model is reading and speaking, so students are mostly involved in verbal mode. It is mostly believed that when students are exposed to linguistic and non-linguistic representations of a concept, real learning is more likely to happen since different memory systems are involved with that concept. Several writers have pointed to the effectiveness of non-verbal representations (Brabec, K., Fisher, K., \& Pitler, H., 2004). This could be assumed a way to incorporate non-linguistic representations into organizing concepts through graphical organizers. Multiple organizers can be used for similar topics. Students may also be asked to write or view images or shapes, create a mental image, construct models, or view movements, and conduct kinetic assignments.

\subsection{The Use of Meta-discipline and Holistic Techniques}

Teaching a same concept in different disciplines will reinforce the variety of memorizing techniques or long-term memory transfer (Bernsen, 1994). Learning will be improved if more classes are designed in an interdisciplinary way. It is also easier to learn interdisciplinary activities that bind different areas of learning, and enjoy the benefits of communication between different types of learning and involve different memory circuits. Applying the curriculum in which interconnected experiences from the perspective of different curricula are provided is the best way to implement holistic learning. This kind of learning is much more stable than learning isolated concepts.

\subsection{Plan Authentic Lessons}

Authentic learning experiences are the ones that are basically true because of the linkage of new information with past experiences for the learner. As soon as we compare the new information with our prior knowledge, a connection will be made between the two which enhances learning (Schacter, 1996). Therefore, genuine activities are those that 
give students the opportunity to see the world around them, through which they associate past experiences with what they already know.

\subsection{Use Product, Process and Progress Evaluations}

Typically, a "product" contains items such as examination, final project, a quiz, and short articles. In other words, it is assumed that a task or achievement which is presented at a given time. Product evaluations are usually summative, but process evaluations are divided into finer stages to achieve the final achievement. One way to increase the efficiency of process evaluation is that considering the embedded assessment. When it comes to improving students' learning outcomes, there is no doubt that thoughtful, embedded and formative assessments is preferable to determine the degree of action based on the final grades (Yorke, 2003). The purpose of the embedded assessment is that you do not have to call the students to test them! Instead, the assessment takes place within the context of everyday activities. This means that there is no separate time for evaluation. Instead, evaluation takes place throughout classroom activities (Wiliam, 2011). Evaluation activities that are in an interconnected form with a classroom will achieve many goals. First, they mostly happen frequently, and this provides a better report of students' academic status. Secondly, since this type of evaluation is repeated frequently, teachers can regulate their instruction in order to prevent failure. Third, they are not coming with the burden of stress, like the summative assessments. Fourth, teachers spend a lot of time teaching instead of assessing learners and scoring them.

\subsection{Developing Explicit Learning Objectives}

According to the research, most of exploratory learning techniques are misleading and an inefficient use of time due to the lack of clear learning goals (Kirscgner, P. A., Sweller, J., \& Clark, R. E., 2006). Clearly stating objectives provides clear guidance for students and they are more likely to achieve learning targets (Marzano, 2009). SMART targets (specific, measurable, attainable, relevant and targeted) are a great guide to the educational system. The smart method, just like many other ideas which assisted pedagogy, was created by the business world to measure the outcomes and consequences, and then enter the education system (Meyer, 2003) .

\subsection{Thinking and Reflective Practices}

The act of articulation (written or oral) brings thinking from superficial to deep learning and improves the quality of understanding. Reflection gives the brain the chance to return to things that known, and occasionally reinforce their paths. In fact, brain reassesses the prior knowledge through comparing what really happens and what is thought to be happening. The neuroscience of decision-making is closely related to reflective practice (Capelo, C., \& Dias, J., 2009). Decisions provide a hierarchy of ideas and thoughts, and reflective practice allows us to learn from the concepts we have received.

\subsection{Use of Collaborative and Democratic Activities}

Social collaboration is a new field in Cognitive Neuroscience and is rapidly expanding to study the mechanisms of neural, hormonal, cellular, and genetic which are underlying social behavior and provides hard evidence to support collaborative learning activities in the classrooms. Class activities encourage the idea that every member has not only the right but also a responsibility to contribute. (Cacioppo, J. T., Berntson, G. G., \& Decety, D., 2010) In addition, these activities will attract the attention of students and mentors because each participant should be at the center of attention. A balanced distribution of power in creating a classroom learning support is essential (Mitchell, M. M., Bradshaw, C. P., \& Leaf, P. J., 2010).

\subsection{Prepare Students to Set Personal Objectives and Give Themselves Feedback}

Part of being an autonomous learner, depends on knowing how to set targets, determining paths to achieving goals, or making a clear way for self-assessment. Autonomous learners are not waiting for others' judgments about their actions or their successes and efforts. The ability to provide feedback is important in achieving personal goals. Mynard and Navarro Argue that the assessment of learning progress should be developed at various levels: peer- topeer, learner- to- advisor, and the internal dialogue (Mynard, J., \& Navarro, D., 2010). Ligorio also agrees with this idea, has analyzed the way in which teachers can foster the internal and communal identity of the students that motivates learning (Ligorio, 2010). Therefore, following a successful modeling of how learning goals are set, teachers should guide the students through an internal dialogue for their continuous improvement. Students who are empowered in the objective-setting cycle will be lifelong learners.

\subsection{Technology and Flipped Classroom}

There is some evidence to support that technology, like experiences, changes the brain (Howard-Jones, P. A., \& Fenton, K., 2011). However, there is a little direct evidence of how this happens in the classroom. Flipped 
classrooms could be an example for using technology that takes the advantage of what we know about the brain and learning. The flipped classroom takes into account the fact that each brain is unique and it is organized in its own way. The flipped classroom structure allows teachers to meet the needs of each student in a completely individual way. The flipped classroom also assumes the fact that not all brains are good at everything, so different students will practice more on different concepts. The flipped classroom allows students to review the lesson as many times as necessary on an individual basis. Furthermore, some students want to hear information, while others want to read the content again and write down the important points. The flipped classroom provides these options. The brain looks for novelty and offers information in various formats to help the memory system. Feedback is vital for learning, and the flipped classroom creates more time and space for interaction between the teacher and the students. The format of flipped classroom also suggests that, in contrast to simple theoretical information exchange, much more practice is done on concepts. The flipped classroom reduces concerns because questioning occurs in a non-threatening way (face-to-face contact or via email), in the absence of other classmates. The flipped classroom uses technology to improve learning experiences and compatible with many principles of the science of mind, brain, and education.

\subsection{Begin Year- Round Schooling}

The current academic calendar was designed for the 1900s agricultural society, in which there were no services, technology, and knowledge-based society at the opening of 21 st Century. Learning activities increase learning in small increments, yet large gaps (as in several consecutive months) lead to forgetfulness based on the brain's tendency to "use it, or lose it." (Hebb, 1949). The forgetfulness that occurs during the summer postpones the learning process. Therefore, this gap between the learning moments reduces memory strengths and many teachers can testify this. This makes the teachers spend at least the first month of the academic year to review the contents of the past year to start the new lessons (Cooper, 2004). Therefore, a year-round calendar, which is offered, suggests that students will have the same number of school days. However, these days distribute across the 12 months with four or six weeks of school and then a small break. In other words, we have four two-to-three- week breaks spread throughout the calendar. The greatest benefit of year-round schooling is the continued improvement of learning, especially for those who need more: many studies show that summer learning loss are detrimental and minorities and deprived students are more vulnerable.

\section{National Curriculum in Iran}

The structure of educational system in the Islamic Republic of Iran is 1-6-6. The length of education in the education system, including the pre-school age, is 13 years, which includes one year of preschool, 6 years of elementary school and 6 years of secondary (high school) school. Secondary education is divided into two stages of the first and second three years. General education includes elementary and the first secondary education and specialized education includes the second secondary school comprising three theoretical, technical and knowledge branches. Students enter one of these three disciplines according to their interests. At the end of high school, diplomas will be awarded to graduates. In Iran, the national curriculum is first developed, followed by a curriculum guide, a school curriculum, and finally a textbook by the research organization. Therefore, the details of the objectives and contents of each area in Iran are presented at these levels.

In the study of "the Fundamental Reform Document of Education" (FRDE), in the formal education system and the national curriculum, we face a Qur'anic term called "good life", which is defined as "the pure and innocent life" and is far from contaminating the areas of education, and its ultimate end (goal) is to receive the blessings of Allah Almighty.

Achieving this goal has a degree in which each individual can achieve some degree of "pure life" in a degree of his life. Reaching to each level depends on factors:

1. Nature, talents and abilities

2. Stages of natural and natural growth

3. A suitable environment for learning

4. Individual effort and desire

To achieve this, we must keep in mind that people have different abilities and talents, and they are not expected to achieve the same level of pure life. Therefore, the concept of the good life is away from the sources of anti-existence and reaching some of the beneficial and productive resources, which is definitely suspicious along with devotion and commitment (Raisdana, Advances in the concept of "good life" in the Fundamental Reform Document of Education 
and national curriculum, 2014).

\section{National Curriculum in the UK}

The structure of educational system in the UK is divided into four key stages. The first key stage is ages 5 to 7 years, the second key stage is ages 8-11, the third key stage is the age of 11-14, and the fourth key stage is 14 to 16 years old. The UK National Curriculum includes 12 subjects. All of these subjects are taught from the first key stage, but the complexity and details of each subject increase with age. Core subjects include mathematics, sciences and English, and the foundation subjects include general lessons. At Key Stage 4, some subjects are not compulsory in the national curriculum after age of 14, but all pupils should study one of these subjects. These subjects include arts (which include art and design, music, dance, drama and media arts), design and technology, humanities (including geography and history) and modern foreign language. Religious, sex and relationship education are not included in the subjects but religious education is taught at all key stages and sex and relationship education is taught at the key stage 3.

"All schools must publish their school curriculum by subject and academic year online. The national curriculum provides an outline of core knowledge around which teachers can develop exciting and stimulating lessons to promote the development of pupils' knowledge, understanding and skills as part of the wider school curriculum.In England, Schools are free to choose how they organize their school day, as long as the content of the national curriculum programs of study is taught to all pupils" (Department for Education,National curriculum in England, 2014, p. 5).

In October 1998, the Department for Education and Employment (DfEE) undertook a survey of evaluations of thinking skills and related areas. The purpose of this review is to analyze what is now understood as "thinking skills" and their role in the learning process. In other words, it aims to identify approaches to developing children's thinking and assess their self-efficacy, to examine how teachers are able to integrate teaching "thinking skills" through different subjects and across the curriculum (McGuinness, 1999). The report suggests how teaching should be done openly, and emphasizing "the quality of thinking processes and thinking skills" is a means to raise standards. Therefore, the approach of thinking skills was adopted in the curriculum in England.

\section{Research Related to Educational System in Iran and the UK}

According to the objectives of this research, we refer to the similar studies carried out as a comparative study of the higher education system of Iran and the UK. A comparative study of Iran and the UK's higher education system was conducted in 2016 by Ismail Ghassemi and Mehdi Seddiqian. The study emphasizes the role of higher education in society and believes that higher education is helpful for the promotion of knowledge, educating professional workforce, gain a deeper attitude towards scientific and cultural viewpoints, and believes that university is an important tool in the development of an advanced society. Therefore, it compares Iran as one of the developing countries, the UK, which is one of the most popular countries in the world in terms of the academic system, based on factors such as methods and how to admit students, grades and courses, educational assessment, educational costs, educational calendar, and the quality of education in these two countries. Besides, it seeks to examine how to provide educational services, the similarities and differences between the two countries' higher education systems, and how the UK's top universities are becoming the best in the world. The findings of this study showed that Iran's higher education system is similar to the higher education system of the United Kingdom in terms of educational programs and courses, but in other cases, there are significant differences between the two systems. The research ultimately addresses the question of why British universities in the world have won the highest scientific rank, stating that this country has taken the path of research into its educational path (Ghassem, Is., \& Seddiqian, M., 2016).

Another research was conducted as a comparative study of the elementary education system of Iran and the UK in 2016 by Hassan Rabbani, Hamid Reza Elhami, Ahmad Reza Pourmanfard and Abbas Noor Mohammadi Devin. The study emphasizes the importance of education and states that it is the most important factors for individuals and societies. Therefore, all nations must pay particular attention to planning and educational reforms, according to the latest educational methods. For this purpose, comparative research can be used to compare the educational system of Iran with the leading countries, including England. The purpose of this research was to investigate the comparative model of the primary education system of Iran and England and to explain the principles and general objectives of the primary education system, which has been developed by analytical-documentary method. The results of this research have shown that the England has a better educational condition than Iran, and Iran has a long way to achieve 
this desirable educational situation. In Iran, many of the objectives of the extra-curricular activities are general, and emphasize attitudes, while in England, Objectives are very clear and precisely aligned with the thoughts of naturalism and empiricism that govern the education system of this country (Rabani, H., Elham, H., Pourmanfard, A., \& Abbas Noor, M., 2016).

In addition, Mubaraki has conducted a research paper titled "Analytical and Comparative Study of Elementary Education in England and Iran". The results show that the UK's education, with its decentralized structure, has provided grounds for the creativity and capabilities of the regions and with the cooperation of universities, the training of the best teachers, and the high level of welfare facilities, has provided a platform for attracting the best people. The National Curriculum also provides a framework for using the capabilities of areas within a defined framework (Mubaraki, 2007).

In this study, as it was stated before, various research has been conducted on comparing higher education and elementary education in Iran and the UK and have offered suggestions for improving the educational system. In this regard, a study has been conducted to examine and compare the national curriculum and provide solutions to improve the educational system in Iran. However, there has not been any study to examine and compare the national curriculum and provide solutions to improve teaching and learning processes, which we are discussing in this study, to analyze the main focus of the educational system that is the National curriculum of Iran. This curriculum is actually the storage for any academic planning and including the contents and objectives of the curriculum.

\section{Method}

According to accessible source of information, nature of the subject, considered goals and questions, this study is a qualitative and a comparative-analytic research. The research method in this study is based on comparative analysis. We compiled qualitative data on the educational systems of the two countries and described them by classifying them together. We also tried to verify the features of the National curriculum in Iran and the UK and to compare them based on the considered principles including mind, brain, and education.

The method, which was applied in this research, is content analysis. First, the main components of the national curriculum of Iran and the UK were determined. They include: aims, learning areas, learning outcomes in each area, the considered approach in each learning area, technology and learning, the principles and the challenges of the education, the principles of selecting proper teaching- learning strategies, assessment and evaluation system, production and implementation process of curriculum, the foundation of curriculum, educational structure and educational time. Then, based on the principles of mind, brain, and education that Tracey Takuhama- Espinosa has introduced in the book of "making classrooms better", we have examined the extent to which these principles were observed in these two national curriculum. We selected some of those principles that are related to the national curriculum. They include: teaching models, the use of meta-discipline and holistic techniques, authentic learning experiences, use of product, process and progress evaluations, developing explicit learning objectives, how to benefit from thinking and reflective practices, using collaborative and democratic activities, preparing students to set personal objectives and giving themselves feedback, technology and flipped classrooms, and begin Year- Round Schooling.

\section{Results}

When the main components of the national curriculum of the two countries of Iran and the UK were selected, they are compared according to mind, brain, and education principles, summarized below: 
Table 1. Compare the National Curriculum in Iran and the UK

\begin{tabular}{|c|c|c|}
\hline & Principles & Analysis \\
\hline 1 & Teaching Models & $\begin{array}{l}\text { Based on the selected principles for the best teaching and learning strategies, it } \\
\text { can be argued that both programs point to a variety of teaching models, including: } \\
\text { building knowledge, understanding and solving problems, providing } \\
\text { opportunities for reviewing prior knowledge and integrating the new information } \\
\text { with experiences, providing opportunities for analysis, interpretation, interaction, } \\
\text { and participation of students and teachers in the learning environment. I.e. in } \\
\text { mathematic subject (Iranian National Curriculum, 2013, p. 25) and in Languages } \\
\text { subject (Department for Education,National curriculum in England, 2014, p. } \\
\text { 252). }\end{array}$ \\
\hline 2 & $\begin{array}{l}\text { The use } \\
\text { Meta-discipline } \\
\text { Holistic approaches }\end{array}$ & $\begin{array}{l}\text { In the national curriculum of Iran, the integration between knowledge domains is } \\
\text { mentioned in a meaningful way Also, in some other parts the combination of } \\
\text { some subjects has been pointed out. For example, "art and culture" course is } \\
\text { of } \text { introduced as meta-curriculum. Besides, it is suggested to integrate "life skills }_{\text {nd }} \text { and the foundation of the family" with other subjects (Iranian National } \\
\text { Curriculum, 2013, p. 27). However, in the national curriculum of the UK, the } \\
\text { relationship between knowledge domains is also more precise. For example, in } \\
\text { Design and Technology subject, it has been mentioned which subjects are } \\
\text { combined with mathematics, design and technology, and computer science. } \\
\text { (Department for Education,National curriculum in England, 2014, p. 234) }\end{array}$ \\
\hline 3 & $\begin{array}{l}\text { Authentic learning } \\
\text { experiences }\end{array}$ & $\begin{array}{l}\text { Both national curriculums refer to authentic and real learning experiences and } \\
\text { demand learning through real experiences. Nevertheless, the national curriculum } \\
\text { of Iran is more general, more comprehensive, and case-based. I.e. in the learning } \\
\text { outcomes of each subject, almost all subjects refer to use of experiences and in } \\
\text { the principles and challenges of education, refers to real experience (Iranian } \\
\text { National Curriculum, 2013, p. 10). While in the national curriculum of the UK, } \\
\text { learning can look at real-life in a more tangible and detailed way and it describes } \\
\text { how this learning occurs. For example, the design and technology subject points } \\
\text { to the principles of nutrition science and how to cook (Department for } \\
\text { Education,National curriculum in England, 2014, p. 234). }\end{array}$ \\
\hline 4 & $\begin{array}{l}\text { Use of product, process } \\
\text { and progress Evaluations }\end{array}$ & $\begin{array}{l}\text { Both national curriculums refer to product and progress evaluation. For example, } \\
\text { In the national curriculum of Iran, it refers to the evaluation of the teaching and } \\
\text { learning process, the product evaluation for passing through the educational } \\
\text { period and progress evaluation to promote academic years and demanding for } \\
\text { combination of these two types of evaluation (Iranian National Curriculum, 2013, } \\
\text { pp. } 40-41 \text { ). Furthermore, the UK's National Curriculum refers to qualitative and } \\
\text { quantitative evaluation, the progress of learning by providing feedback to } \\
\text { students and having scales for their progression (Department for Education, } \\
\text { assessment principles, 2014). However, embedded assessment, which increases } \\
\text { the process evaluation, is not mentioned in both of the national curriculum. }\end{array}$ \\
\hline 5 & $\begin{array}{l}\text { Developing explicit } \\
\text { learning objectives }\end{array}$ & $\begin{array}{l}\text { Learning objectives are expressed in terms of learning outcomes in each area. } \\
\text { Objectives are expressed in both curriculums. In the UK, however, the goals are } \\
\text { explicitly and defined at each key stage and each academic year, for example in } \\
\text { the subject of English, the purpose of study and aim are mentioned for all key } \\
\text { stages (Department for Education, National curriculum in England, 2014, pp. } \\
\text { 20-80). On the contrary, in the national curriculum of Iran, the goals are } \\
\text { expressed in a more general and comprehensive way and they do not focus on } \\
\text { details at different levels of education. Therefore, there are not so clear goals in } \\
\text { Iran's national curriculum. I.e. in physical education subject, there are some } \\
\text { items, which are mentioned as its goal for academic years (Iranian National } \\
\text { Curriculum, 2013, p. 30). }\end{array}$ \\
\hline
\end{tabular}


6 Thinking and Reflective practices

7 Use of collaborative and democratic activities

8 Prepare students to set personal objectives and give themselves feedback

9 Technology and flipped Classrooms

10 Begin Year- Round Schooling
In both national curriculums, the processes of thinking and reflection and the creation of opportunities to create these skills are referred. The only difference between the two curriculums is that in the national curriculum of Iran, there is a greater emphasis on thinking, reflection, and its leading role among various goals (Iranian National Curriculum, 2013, p. 17); however, it does not insist on creating opportunities for reflection. On the other hand, in the National curriculum of the UK focuses more on creating opportunities for thinking and more specifically refers to the acquisition of thinking skills. I.e. in subject science, it refers to conceptual understanding, answer scientific questions, able to describe associated processes, collecting, presenting and analyzing data. (Department for Education,National curriculum in England, 2014, p. 168)

Both national curriculums refer to the participation of students and teachers. Nevertheless, the participatory opportunities that are featured in the National curriculum of Iran are completely different form the UK's national curriculum. In the Iran's national curriculum, all the headings, content, evaluation and budgeting are planning at the national level and students and teachers do not participate in designing lessons. On the contrary, in the UK's national curriculum, clearly asserts that "The national curriculum forms one part of the school curriculum" and "Schools are also free to include other subjects or topics of their choice in planning and designing their own program of education" (Department for Education,National curriculum in England, 2014, p. 5)

In the national curriculum of Iran and the UK, there is no mention of the recognition of personal objectives, internal dialog and self-feedback. Although in the UK's national curriculum, in each subject, refers to "use discussion in order to learn", "participating in debate" and "explain clearly their understanding and ideas" which lead to self- feedback and dialog." (Department for Education,National curriculum in England, 2014, p. 14).

However, there are some references to the needs, talents and individual differences of students in some cases. As a result, it may be possible to interpret the recognition of personal goals with respect to individual differences.

In both national curriculums, technology and its use are mentioned. However, in the National curriculum of the UK, there is a subject on computing that refers more to computer science, programming, and information and communication technology. It also refers to" recognize common uses of information technology beyond school" (Department for Education,National curriculum in England, 2014, p. 230). Therefore, it can be argued that the use of technology in the UK's national curriculum can be seen more.On the other hand, in Iran's national curriculum refers to the use of virtual environments for teachers and learners (Iranian National Curriculum, 2013). However, in either of the two curriculum, learning via flipped classroom is not mentioned specifically.

In the national curriculum of Iran, there is no reference to the division of the year into semester, and refers only to the number of hours taught at each academic year. It is also mentioned as the academic year increases, the training hour will increase. It also introduces the academic year as a full year, begins on the first of October each year and will continue until the end of September of the following year (Iranian National Curriculum, 2013, pp. 47-48). Therefore, this criterion is not met in the national curriculum of Iran.Nonetheless, in the National curriculum of the UK, the school year is generally from September to July although the exact time is different across the UK. Each academic year is divided into three semesters with a half term between semesters (School term and holidays, 2018). 


\section{Discussion and Conclusion}

In the national curriculum of Iran, "thinking and reflection" are two of the five central elements that have a pivotal role. In fact, leading individuals towards thinking is one of the most fundamental duties of the educational system in the Islamic Republic of Iran and is emphasized in the national curriculum of Iran and the document of the philosophy of education. However, what do we mean with regard to reflection and thinking? Are these elements, which are one of the main goals of the education system in Iran, seen in the results? As shown in table 1, the Iranian national curriculum has not provided a systematic model for thinking and the real definition of thinking and its components have not been addressed. Iran just only explains about development of thinking, reasoning, and opportunities for thinking. Furthermore, it is not mentioned how to implement thinking skills in a variety of subjects, and not exemplified how to create thinking, while it is clearly defined in the UK.In the national curriculum of the UK, the definition and use of these skills can be seen in purpose of each subject. It is also seen that subjects are being done using reasoning, information processing, analysis, and observation, and one can clearly see how to apply these thinking skills. As in the study conducted by Carroll McGuinness, the emphasis is on the thinking skills in the educational system and its aim was to understand the meaning of thinking skills and their role in the learning process. (McGuinness, 1999). Therefore, the UK Department of Education responded to this request and included a systematic pattern for thinking skills in the curriculum. As a result, in the National curriculum of the UK, various opportunities are observed for the implementation of thinking skills in learning programs.

Moreover, in the National Curriculum of the UK, "computing" is a subject in the curriculum, and it focuses on teaching this subject. Michael Hammond states in an article that today, much effort is needed in learning and teaching to increase the use of information and communication technology since it puts a potential impact on educational standards and helps to develop a curriculum that is socially and professionally important (Hammond, 2014). Thus, the National curriculum of the UK considers a great importance of digital literacy since they believe that through the concepts of computer science students can develop their ideas, learn the fundamentals of computer science, and be creative and reliable users of information and communication technology. This subject is also combined with other subjects in the national curriculum so that it can be used in other areas. Nevertheless, although in Iran it is emphasized to apply technology and learning in a variety of areas, there is not specific area considered for learning technology, and the importance of computer literacy has not been highlighted. However, as illustrated in table 1, both of the national curriculum do not use the flipped classrooms, which meet the needs of each student and consider the fact that students have different abilities. Thus, it is better for both of the national curriculum to consider different needs of students via flipped classrooms to make learning enjoyable.

In this research, as mentioned before, the academic year in Iran and the UK is different. In general, the national curriculum of Iran states that the school period is one year (from October 1st to September of the following year). However, the school year starts from October and lasts until June of the following year. So, how can one claim that in Iran, the school year is one year? In the same vein, Qasemi and Sedighian in their research confirmed that the school year is from October 1 to June 30. So, there seems to be contradictions in the national curriculum about a school yearand as shown in table 1, this principle is not followed by schools or at least we are not aware of that (Ghassem, Is., \& Seddiqian, M., 2016). On the other hand, in the UK, the academic year begins from the first of September to the end of July and the year is divided into 3 semesters with 3 half-term break. Therefore, there is not a long gap between the academic years, and as a result, the students are less likely to forget their lessons. However, in Iran, the schools are closed for a total of three months and this phenomenon may have an adverse effect on students' memory. Therefore, it seems necessary for curriculum planners and policy makers to take a reflection on the educational calendar at the national level so that the memory capacity of the students is not reduced and can provide a higher quality of the school year.

Furthermore, it is shown in table 1 that in Iran, learning goals are generally expressed in various domains although they are not explicitly explained. As in the research conducted by Hassan Rabbani and his colleagues, it is pointed out that the aims are not clear and precise, and leads to confusion among custodians and performers (Rabani, H., Elham, H., Pourmanfard, A., \& Abbas Noor, M., 2016). However, the aims are clearly defined in the national curriculum of the UK. Since the structure of the syllabus of the two countries was different, the goals of explicit learning in Iran were expressed at lower levels (curriculum guidelines, curriculum for schools and textbooks). Nevertheless, this issue is beyond the scope of this study.

Another aspect, which is mentioned in table 1, is applying embedded evaluations for students. These two curriculum do not meet this principle. Although product and process evaluations are somehow mentioned in the curriculum of the two countries and they are important, we should not lose sight of the fact that some students do not show their 
abilities and knowledge through examinations, projects, etc. The assessments should take place within the context of everyday activities. These types of evaluations can make the teacher to become aware of students' academic status, regulate the instruction according to their abilities and decrease the burden of stress for students. Teachers also can spend a lot of time teaching instead of assessing learners and scoring them.

\section{Conflict of interest statement}

All authors do not have any conflicts of interest that are related to this study.

\section{References}

Bernsen, N. O. (1994). Foundations of multimodal representations: A taxonomy of representational modalities. Interacting with Computers, 6(4), 347-371. https://doi.org/10.1016/0953-5438(94)90008-6

Brabec, K., Fisher, K., \& Pitler, H. (2004). Building better instruction: How technology supports nine research-proven instructional strategies. Learning \& Leading with Technology, 31, 6-11.

Cacioppo, J. T., Berntson, G. G., \& Decety, D. (2010). Social neuroscience and Its relationship to social psychology. Social Cognition, 28, 675-685. https://doi.org/10.1521/soco.2010.28.6.675

Capelo, C., \& Dias, J. (2009). A feedback learning and mental models perspective on strategic decision making. Educational Technology, Research and Development, 57(5), 629-644. https://doi.org/10.1007/s11423-009-9123-z

Cooper, H. (2004). Year round schooling gives students a boost. Retrieved from DukeTODAY.

Department for Education, assessment principles. (2014, April 16). Retrieved from https://www.gov.uk/government/publications/assessment-principles-school-curriculum

Department for Education,National curriculum in England. (2014). Retrieved from https://www.gov.uk/government/publications/national-curriculum-in-england-primary-curriculum

Ghassem, Is., \& Seddiqian, M. (2016). Comparative Study of Higher Education System in Iran and England. Quarterly Journal of Farahi Kutgan, 45-84.

Hammond, M. (2014). Introducing ICT in schools in England: Rationale and consequences. British Journal of Educational Technology, 2(11), 191-201. https://doi.org/10.1111/bjet.12033

Haywood, H. C. (2013). What is cognitive education? Cognitive education and psychology, 26-44.

Hebb, D. O. (1949). The organization of behavior. New York: Wiley. https://doi.org/10.1016/S0361-9230(99)00182-3.

Howard-Jones, P. A., \& Fenton, K. (2011). The need for interdisciplinary dialogue in developing ethical approaches to neuroeducational research. Neuroethics, 5(2), 119-134. https://doi.org/10.1007/s12152-011-9101-0

Iranian National Curriculum. (2013). Retrieved from http://cfu.ac.ir/file/2/attach201404326047545426747.pdf

Jefferies, M. J., \& Hancock, T. (2002). Thinking skills: A teachers 's guide. Hopscotch Educational Publishing Ltd.

Kirscgner, P. A., Sweller, J., \& Clark, R. E. (2006). Why minimal guidance during instruction does not work: An analysis of the failure of constructivist, discovery, problem- based, experienctial, and inquiry-based teaching. Educational Psyghologist, 41(2), 75-86. https://doi.org/10.1207/s15326985ep4102_1

Ligorio, M. B. (2010). Dialogical relationship between identity and learning. Culture \& Psyghology, 16(1), 93-107. https://doi.org/10.1177/1354067X09353206

Marzano, R. J. (2009). The art and science of teaching: A comprehensive framework for effective instruction. Alexandria, VA: Association for Supervision and Curriculum Development.

McGuinness, C. (1999). From thinking skills to thinking classrooms. Britain: Department for Education and Employment.

Meyer, P. J. (2003). Attitude is everything: If you want to succeed above and beyond. Monterrey, CA: Meyer Resource Group, Incorporated.

Mitchell, M. M., Bradshaw, C. P., \& Leaf, P. J. (2010). Student and teacher perceptions of school climate: A multilevel exploration of patterns of discrepancy. Journal of School Health, 80(6), 271-279. 
https://doi.org/10.1111/j.1746-1561.2010.00501.x

Mubaraki, N. (2007). Analytical and Comparative Study of Elementary Education in England and Iran(in persian). Tehran: Allame tabatabai university.

Mynard, J., \& Navarro, D. (2010). Dialogue in self-access learning. In A. M. Stoke (Ed.), JALT2009 Conference Proceedings (pp. 95-102). Tokyo: JALT.

O’Donnell, A. M., Dansereau, D. F., \& Hall, R. H. (2002). Knowledge maps as scaffolds for cognitive processing. Educational psychology review, 14(1), 71-86. https://doi.org/10.1023/A:1013132527007

Rabani, H., Elham, H., Pourmanfard, A., \& Abbas Noor, M. (2016). Comparative Study of the Elementary Education System of Iran and England. The first international conference on modern researchES in the field of educational science \& psychology and social studies of Iran. Qom: soroush hekmat.

Raisdana, F. (2010). ROSHD information technology. National curriculum: features and range, pp. 24-26.

Raisdana, F. (2014). Advances in the concept of "good life" in the Fundamental Reform Document of Education and national curriculum. Educational technology of ROSHD, 29(7), 1-3.

Schacter, D. (1996). Searching for memory: The brain, the mind. And the past. School term and holidays. (2018, October 1). Retrieved from https://www.gov.uk/school-term-holiday-dates.

Tokuhama- Espinosa, T. (2014). Making Classroms Better: 50 practical applications of Mind, Brain and Education Science.

Wiliam, D. (2011). Embedded, formative assessment. Broomington: tree solution.

Yorke, M. (2003). Formative assessment in higher education: Moves towards theory and the enhancement of pedagogic practice. Higher education, 45(4), 477-501. https://doi.org/10.1023/A:1023967026413 